\title{
Project Management Maturity Models for Construction Firms
}

\author{
Filipe Machado ${ }^{1}$, Nelson Duarte ${ }^{2,3, *(\mathbb{D})}$, António Amaral ${ }^{2,4}$ (D) and Teresa Barros ${ }^{2,3}$ (D) \\ 1 ESTG-P.PORTO, 4610-156 Felgueiras, Portugal; 8180606@estg.ipp.pt \\ 2 CIICESI-ESTG, Politécnico do Porto, 4610-156 Felgueiras, Portugal; sal@isep.ipp.pt (A.A.); \\ tbarros@estg.ipp.pt (T.B.) \\ 3 International Research Institute for Economics and Management, Hong Kong, China \\ 4 ISEP-P.PORTO, 4249-015 Porto, Portugal \\ * Correspondence: nduarte@estg.ipp.pt or duarte.nelson@gmail.com
}

Citation: Machado, Filipe, Nelson Duarte, António Amaral, and Teresa Barros. 2021. Project Management Maturity Models for Construction Firms. Journal of Risk and Financial Management 14: 571. https:// doi.org/10.3390/jrfm14120571

Academic Editor: Cristina Raluca Gh. Popescu

Received: 8 October 2021

Accepted: 29 October 2021

Published: 25 November 2021

Publisher's Note: MDPI stays neutral with regard to jurisdictional claims in published maps and institutional affiliations.

Copyright: (c) 2021 by the authors. Licensee MDPI, Basel, Switzerland. This article is an open access article distributed under the terms and conditions of the Creative Commons Attribution (CC BY) license (https:/ / creativecommons.org/licenses/by/ $4.0 /)$.

\begin{abstract}
This paper aims to identify and analyze project management maturity models in order to identify those best suited to be adopted in construction firms. To do so, models from papers available in academic repositories were analyzed. To be successful, the construction business deeply depends on projects outcomes; thus, the implementation of project management maturity models is important for this sector. A maturity model is a valuable technique to assess project management capabilities within a single part of an organization or to assess an organization as a whole. Its main purpose is to provide a means to create a more organized and predictable way for organizations to achieve their goals, increasing their chances of success regarding the outputs, outcomes, and benefits. In this paper, documentary research was performed to identify available project management maturity models and togather information about their performance. The information gathered was used to find elements to be compared with the identified models. Reviewing the literature, 39 project management maturity models were identified. The authors selected two PMMMs that were well fitted to assess the project management capabilities in construction firms: OPM3 and MMGP Prado.
\end{abstract}

Keywords: maturity model; maturity assessment; project management; construction

\section{Introduction}

The construction industry plays a very significant role in any economy considering the jobs it creates, the cashflows involved, and the infrastructures it develops (Cruz et al. 2019). This sector is formed by several different segments, mostly differentiated by the particular projects executed. Ultimately, the type of project is what defines their strategic positioning (Archibald 2013). Jobs can range from small remodeling interior works and maintenance works to big developments such as airports or shopping centers. Contractors are extremely specialized in a single task or have a more "turnkey" approach, commonly known as engineering, procurement, and construction (Nikjow et al. 2021), yet it is undoubtable that construction companies' purpose aims to execute construction projects. Therefore, within the development and execution of these projects lays the core of their business model. According to Chen et al. (2019), that is what makes them project-based firms (PBFs) and modern, project-based organizations which are common settings for engineering work, complex problem-solving, and interdisciplinary work (Söderlund 2014), not just old-fashioned construction companies.

According to Packendorff and Lindgren (2014), the project form is the preferred methodology for these organizations because of its perception as a controllable way of avoiding all the classic problems of bureaucracy. According to Kwak et al. (2015, p. 1652), through the projectization of organizations, "projects, not departments, become the unit of control and the role of management is to manage the relationships between projects and their environment, both internal (within the company) and external (outside the company)". 
Project management capabilities are a nuclear asset in any PBF, and their financial success relies mostly on project outcomes (Chen et al. 2019). According to Yazici (2010), organizations with higher maturity levels in project management (PM) evidence a better performance while managing their projects to gain or maintain a competitive advantage over their competitors. Prado (2016) states that project management maturity (PMM) and success go hand in hand.

According to the Organizational Project Management Maturity Model-OPM3 ${ }^{\circledR}$ (OPM 2013, p. 240) and The Standard for Organizational Project Management (OPM 2018, p. 46), "organizational project management maturity is the level of an organization's ability to deliver the desired strategic outcomes in a predictable, controllable, and reliable manner". According to Kerzner (2016), a Project Management Model (PMM) consists of the development of systems and processes, which are repetitive by nature, and the assurance that each one of them has a high probability of success. Christoph and Konrad (2014) argue that a project management maturity model (PMMM) is an instrument used to measure an organization's project management capabilities and then attribute a classification that matches a specific maturity level. Silva et al. (2021, p. 811) state that a maturity model $(\mathrm{MM})$ "can be a way of establishing and sustaining collaboration as it helps organizations to evaluate their processes against best practices and propose actions for improvement". According to Prado (2016), a PMMM is an effective mechanism to numerically quantify an organization's capability to govern its projects with success. PMMMs are also expected to develop a maturity improvement plan that is supported in the creation of adequate conditions to evolve and present enduring conditions to maintain high-performance standards, as well as being focused on attaining the project's benefits.

According to Kwak et al. (2015), MMs have evolved over time. They started by addressing process management, then moving to focus on management systems and finally to a more holistic form addressing the organization as a whole. In their study, it was concluded that one of the main advantages of MMs is their ability to increase the effectiveness (the capability of the PMM framework to identify, prioritize, and lead the required improvement actions) and comprehensiveness (the capability that the PMM framework has to cover different aspects of the organization's work) of improvement efforts and gains.

Bearing in mind the brief introduction to the concepts of project management, maturity, and construction business, the present paper aims to identify the best PMMM to be used by construction firms. To achieve this, we implemented a methodological strategy to capture the specificities of the construction sector. Therefore, it is vital to ensure transparency and exemption as well as to develop a road map towards the opportunity to repeat this set of steps and to reach the same conclusions. The next chapter addresses this issue.

\section{Methodology}

As previously mentioned, this article aims to identify and select the best-fitted PMMM to assess the project management capabilities of construction firms using selection criteria based on two stages:

- $\quad$ Stage 1: Identify and compile PMMMs through a literature review in two steps:

Step 1: Identify and comprehend all the different MMs available.

Step 2: Develop a table that summarizes the information gathered in the previous step.

- Stage 2: Select the most suitable MM for assessing PM capabilities in the construction sector in three steps:

Step 1: Choose two selection criteria to comprehend and determine which elements are to be used for the characterization of the identified PMMM.

- Step 2: Develop a comparison table for the identified PMMM using the elements determined in the previous step. 
Step 3: Analyze the information gathered in the comparison table developed in the previous step and cross it with the conclusions from a set of PMMM implementations in the construction sector.

Figure 1 presents a flowchart to better show how this research was developed. It started with the following research question: What is the best-suited PMMM to assess PMM in construction companies?

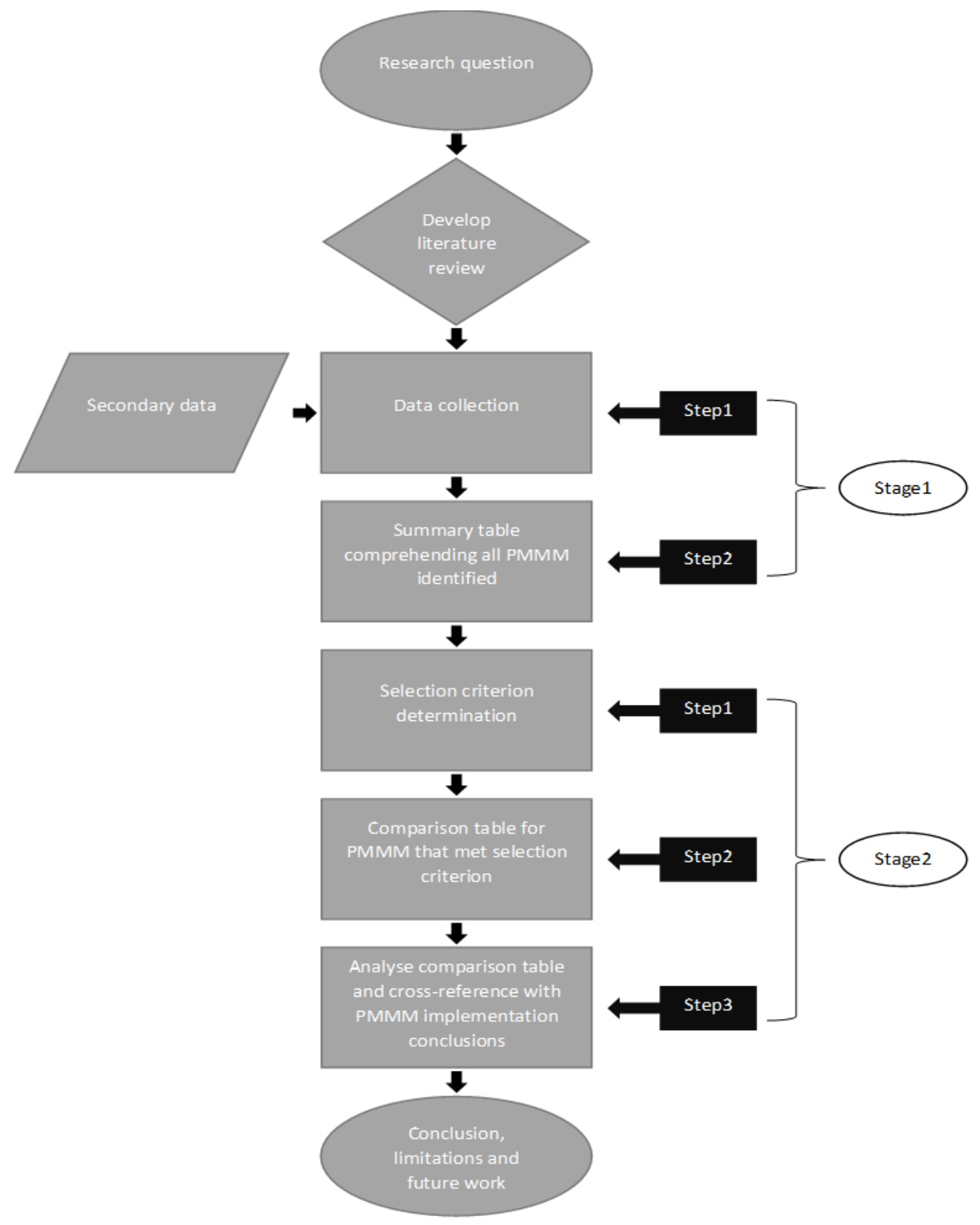

Figure 1. Methodology flowchart.

It was then decided to develop a rigorous literature review, conducted in two stages. For Step 1 of Stage 1, references were collected and identified on scientific databases such as ScienceDirect, b-on, ResearchGate, IEEE Xplore, and Google. Search terms included the keywords "maturity", "maturity model", "capability maturity", and "project management maturity". Then, the authors used backwards snowballing as a secondary search strategy, performed through the database search results. These references were analyzed 
and selected only after being considered relevant for the research. For Step 2, a summary table was developed to comprehend all the PMMMs identified.

On Step 1 of Stage 2 selection criteria were adopted. An exclusion criterion and an inclusion criterion. The first criterion consisted in the fact that selected models should have been implemented in a construction environment. Because of the scarcity of research papers in this domain, we created the following inclusion criterion: the inclusion of papers that had an empirical foundation, where PMMM were applied and analyzed, in order to shed some light on positive and negative aspects, as well as barriers and future research even if in different sectors. Despite this, a search beyond the literature was also pursued to obtain inspiration from the academic community in order to determine the elements to be considered in the characterization of the selected models. For Step 2, a comparison table for the PMMM that met the selection criteria was developed. Finally, Step 3 consisted of analyzing the comparison table and cross-referencing it with the conclusions made by those who have implemented those PMMM in a construction environment.

In the first topic of the next chapter, the authors present an overview of all the PMMM identified.

\section{Analysis of the Maturity Models}

\subsection{Project Management Maturity Models}

This section summarizes the analysis of a set of different MM. Since the 1990s, more than $30 \mathrm{MM}$ have emerged and most of them have a graduation chart set of five levels of maturity. Usually, the classification is aligned as level one-no practice of project management methodologies at all, to level five, the optimum stage of implementation of those methodologies (Pretorius et al. 2012). The authors summarize the MM in a wide range of areas, from software engineering to asset management, information governance and construction management. The goal was to select several maturity models to reflect a diverse approach without focusing on a single area. Table 1 summarizes the information collected from the literature review, the creation of which completes Stage 1, with 39 PMMMs identified.

Table 1. Synthesis of the identified maturity models.

\begin{tabular}{|c|c|c|}
\hline Maturity Model & Source & Area of Implementation \\
\hline ISO/IEC TS 33060:2020 & (ISO/IEC 2020) & Information System (IS) \\
\hline CMMI & $\begin{array}{l}\text { (Backlund et al. 2014; Berssaneti and Carvalho 2015; Monteiro de } \\
\text { Carvalho et al. 2005; Jia et al. 2008; Khoshgoftar and Osman 2009; } \\
\text { Proença and Borbinha 2016) }\end{array}$ & IS/Construction \\
\hline MDD & (Proença and Borbinha 2016; Parviainen et al. 2009) & Industry/Manufacturing/IS \\
\hline MB-V2M2 & (Proença and Borbinha 2016; Belt et al. 2009) & IS \\
\hline DPMM & (Proença and Borbinha 2016; Cook and Visconti 1998) & IS \\
\hline BPMM & (Khoshgoftar and Osman 2009; Proença and Borbinha 2016) & Business Process (BP)/IS \\
\hline OMG BPMM & (Proença and Borbinha 2016; Gardiner et al. 2008) & $\mathrm{BP} / \mathrm{IS}$ \\
\hline MDM DGM & (Nascio 2009) & IS \\
\hline Gartner BPM MM & (Proença and Borbinha 2016; Melenovsky and Sinur 2006) & $\mathrm{BP} / \mathrm{IS}$ \\
\hline Oracle DGMM & (Nascio 2009) & IS \\
\hline GITC MM & (Proença and Borbinha 2016; Hamel et al. 2013) & Information Technology (IT) \\
\hline IT-CMF & (Proença and Borbinha 2016; Carcary 2011) & IT/IS \\
\hline BITA MM & (Proença and Borbinha 2016; Luftman 2011) & IT \\
\hline The IT service CMM & (Proença and Borbinha 2016; Niessink et al. 2005) & IT \\
\hline RMMM & (Proença and Borbinha 2016; Proença et al. 2016) & Education/IS \\
\hline Gartner EIM-MM & (Proença and Borbinha 2016; Nascio 2009) & IS \\
\hline
\end{tabular}


Table 1. Cont

\begin{tabular}{|c|c|c|}
\hline Maturity Model & Source & Area of Implementation \\
\hline RDM MM & (Proença and Borbinha 2016) & IS \\
\hline ECM MM & (Proença and Borbinha 2016; Proença et al. 2016) & IS \\
\hline DataFlux DGMM & (Nascio 2009) & IS \\
\hline DAM MM & (Proença and Borbinha 2016; Proença et al. 2016) & IS \\
\hline EWSoutions DGMM & (Nascio 2009) & IS \\
\hline AMMM & (Proença and Borbinha 2016; Proença et al. 2016) & Asset Management/IS \\
\hline RMM & (Proença and Borbinha 2016) & $\mathrm{BP}$ \\
\hline $\begin{array}{l}\text { IBM Data Governance } \\
\text { Council MM }\end{array}$ & (Nascio 2009) & IS \\
\hline COBIT MM & (Proença and Borbinha 2016) & IT \\
\hline $\begin{array}{l}\text { Knowledge Logistics } \\
\text { DGM }\end{array}$ & (Nascio 2009) & IS \\
\hline IGMM & (Proença and Borbinha 2016; Proença et al. 2016) & IS \\
\hline SDGMM & (Proença and Borbinha 2016) & IS \\
\hline OPM3 & $\begin{array}{l}\text { (Kwak et al. 2015; Backlund et al. 2014; Berssaneti and Carvalho } \\
\text { 2015; Monteiro de Carvalho et al. 2005; Jia et al. 2008; Khoshgoftar } \\
\text { and Osman 2009; Pinto 2013; Pinto and Williams 2013) }\end{array}$ & IT/Construction/BP \\
\hline P3M3 (OGC) & (Jia et al. 2008; Khoshgoftar and Osman 2009) & Construction \\
\hline P2MM-OGC & (Jia et al. 2008; Khoshgoftar and Osman 2009; Pinto 2013) & Construction/BP \\
\hline PMM (Kerzner) & $\begin{array}{l}\text { (Kwak et al. 2015; Berssaneti and Carvalho 2015; Monteiro de } \\
\text { Carvalho et al. 2005; Khoshgoftar and Osman 2009) }\end{array}$ & Construction/BP \\
\hline PM2 (Berkeley) & (Backlund et al. 2014; Khoshgoftar and Osman 2009) & Construction \\
\hline PMMM (Anderson) & (Khoshgoftar and Osman 2009) & - \\
\hline FAA-CMM (SEI) & (Kwak et al. 2015; Khoshgoftar and Osman 2009) & Aviation \\
\hline SPICE & (Backlund et al. 2014; Sarshar et al. 1999) & Construction \\
\hline PMS-PMMM & (Jia et al. 2008; Hillson 2003) & Construction \\
\hline MMGP Prado & $\begin{array}{l}\text { (Dragoni and Ghobril 2020; Neto et al. 2019; Prado 2015; Santos } \\
\text { et al. 2019) }\end{array}$ & IS/IT/Construction \\
\hline P-CMM (People) & (Kwak et al. 2015) & Construction \\
\hline
\end{tabular}

At the beginning of Stage 2, it was necessary to identify the elements that are important for a PMMM. The definition and comprehension of those elements has a meaningful purpose to set a base for comparison between PMMM features and specifications.

Reviewing the literature, it was found a set of authors focused on maturity models (Kwak et al. 2015; Prado 2016; Kerzner 2016; Backlund et al. 2014; Berssaneti and Carvalho 2015; Monteiro de Carvalho et al. 2005; Jia et al. 2008; Khoshgoftar and Osman 2009; Proença and Borbinha 2016; Parviainen et al. 2009; Belt et al. 2009; Cook and Visconti 1998; Gardiner et al. 2008; Nascio 2009; Melenovsky and Sinur 2006; Hamel et al. 2013; Carcary 2011; Luftman 2011; Niessink et al. 2005; Proença et al. 2016; Pinto 2013; Pinto and Williams 2013; Dragoni and Ghobril 2020; Santos et al. 2019; Hillson 2003; Ibbs et al. 2007). A deeper analysis reveals that some predetermined elements were used by Khoshgoftar and Osman (2009). These authors proposed 27 elements to be considered, as follows:

1. Publisher: a reliable publisher.

2. Scope: the cover of the area of model.

3. Number of maturity levels: the number of maturity levels of model.

4. Discrete and continues: consisting of the maturity level of the model. 
5. Details: the number of factors considered.

6. Date of issue: the publications from 2000 to 2007 will be taken into consideration in the study.

7. Refer to standard: based on which standard the model is designed.

8. Definition of maturity: if it contemplates a definition of maturity.

9. Organization strategy: considering the strategy of the organization.

10. Project management process: covering the project management process.

11. Program management process: covering the program management process.

12. Portfolio management process: the covering of the portfolio management process.

13. Coverage assessment: identifying the model's coverage.

14. Assessment difficulty: the extent of difficulties.

15. Assessment cost: expenditure of assessment.

16. Quantitative results: showing the quantitative results.

17. Tangible results: identifying the results clearly.

18. Identifying weak and strong points: indicating weaknesses and strongest points of the organization.

19. Continuous assessment: considering continuous assessment.

20. Training difficulty: the extent of difficulties in the training of the model for staff and assessors.

21. Commitment for continuous improvement: considering the continuous improvement.

22. Suggestion of alternative for improvement: determining the priority of improvement in an organization.

23. Priority of improvement: determining the priority of improvement in the organization.

24. Support by publisher: support by publisher.

25. New edition: compatibility with new conditions.

26. Easy for execution: execution of model easily.

27. Simple and understandable: simple and understandable.

Throughout the OPM $3{ }^{\circledR}$ Program, many contributors during the development of the model played the task of identifying PMMM elements to set them apart (Kwak et al. 2015; Cooke-Davies et al. 2001). All the mentioned authors made efforts in order to differentiate the PMMM from each other, but the research of Kwak et al. (2015) was considered more focused on the common elements and grouped them, as follows:

1. Appraisal:

a. Providing a self-assessment;

b. Evaluating the effectiveness of actions.

2. Body of knowledge

a. Describing the concept of maturity;

b. Defining maturity levels;

c. Defining maturity paths;

d. Presenting practices required for improving maturity;

e. Dependency on a specific standard;

f. Apply incremental changes.

3. Improvement

a. Evaluating the effectiveness of improvement actions;

b. Continuous improvement as the last level of maturity;

c. Applying incremental improvement changes.

As is plausible by the number of MM identified, there is no "one size fits all" type of model. This means that choosing the right model demands taking into account the requirements of each project, studying the different models available and tailoring them to meet the specific characteristics of the project. Considering the previous proposals and peculiarities, it was determined that this research would choose eight elements from 
Khoshgoftar and Osman's (2009) work (number of levels; maturity definition; assessment cost; strong/weak points identification; continuous assessment; improvement opportunities prioritization; author support availability; continuity between versions) and group them into three categories to differentiate the PMMM identified. These categories were inspired by the research of Kwak et al. (2015). As previously shown, they developed three groups: appraisal, body of knowledge and improvement. Because we believe that the pieces of evidence of improvement actions must appear during the appraisal phase, the authors joined both appraisal and improvement together. The authors considered that an important element of choice for a PMMM would be the amount of support that the author/owner/developer can give, and also whether or not it was a model being continuously developed and supported with no gaps between the newer version and the one before that. Taking this into account, a new group was created to satisfy this particular need and properly address these issues.

The developed groups, as well as the definitions of each element, are presented as follows:

(1) Model Structure (Table 2):

a. Number of levels: quantifies the number of maturity levels presented in the model;

b. Maturity definition: verifies that the model provides a clear definition of maturity.

(2) Model Assessment (Table 3):

a. Assessment cost: indicates the degree of cost of an assessment project;

b. Strong/weak points' identification: checks whether the model identifies strengths/weak of the organization;

c. Continuous assessment: verifies that the model is eligible for continuous assessment;

d. Improvement opportunities prioritization: checks whether the model identifies a priority for improvement in the organization.

(3) Model support (Table 4):

a. Author support availability: indicates the degree of support that the author is capable of providing for the model;

b. Continuity from different versions: checks that there is more than one version of the model, and if so, whether there is a continuity between them.

By the analysis of Tables 2-4, it is possible to observe that not all selected articles had all the information needed to fulfil all the pointed features. For this reason, they were indicated with a question mark.

Table 2. Synthesis of the identified maturity models regarding structure.

\begin{tabular}{ccc}
\hline Maturity Model & Number of Levels & Maturity Definition \\
\hline CMMI-SEI & 5 & Yes \\
OPM3 (PMI) & 4 & Yes \\
P3M3 (OGC) & 5 & Yes \\
Prince2 Maturity Model (PMM2-OGC) & 5 & Yes (medium) \\
PMM (Kerzner) & 5 & Yes (medium) \\
PM2 (Berkeley) & 5 & Yes (medium) \\
SPICE & 5 & Yes (medium) \\
PMS-PMMM & 5 & No \\
MMGP Prado & 5 & Yes \\
\hline
\end{tabular}


Table 3. Synthesis of the identified maturity models regarding assessment.

\begin{tabular}{ccccc}
\hline Maturity Model & $\begin{array}{c}\text { Assessment } \\
\text { Cost }\end{array}$ & $\begin{array}{c}\text { Strong/Weak Points } \\
\text { Identification }\end{array}$ & $\begin{array}{c}\text { Continuous } \\
\text { Assessment }\end{array}$ & $\begin{array}{c}\text { Improvement Opportunities } \\
\text { Prioritization }\end{array}$ \\
\hline CMMI-SEI & High & Yes & Yes & Yes \\
OPM3 (PMI) & Low & Yes & Yes & Yes \\
P3M3 (OGC) & High & $?$ & Yes & Yes (low) \\
Prince2 Maturity Model & High & $?$ & Yes (medium) & Yes (low) \\
(PMM2-OGC) & Low & Yes & Yes (medium) & Yes (medium) \\
PMM (Kerzner) & High & Yes & Yes (medium) & $?$ \\
PM2 (Berkeley) & Medium & Yes & Yes (medium) & Yes (medium) \\
SPICE & $?$ & Yes & No & Yes (low) \\
PMS-PMMM & Low & Yes & Yes &
\end{tabular}

Table 4. Synthesis of the identified maturity models regarding support.

\begin{tabular}{ccc}
\hline Maturity Model & $\begin{array}{c}\text { Author Support } \\
\text { Availability }\end{array}$ & $\begin{array}{c}\text { Continuity from } \\
\text { Different Versions }\end{array}$ \\
\hline CMMI-SEI & High & Yes \\
OPM3 (PMI) & High & Yes \\
P3M3 (OGC) & High & Yes \\
Prince2 Maturity Model (PMM2-OGC) & High & Yes \\
PMM (Kerzner) & High & Yes \\
PM2 (Berkeley) & Low & $?$ \\
SPICE & Medium & Yes \\
PMS-PMMM & $?$ & $?$ \\
MMGP Prado & High & Yes \\
\hline
\end{tabular}

There were seven articles identified and analyzed which focused on the application of PMMM to the construction sector. These articles compared or categorized nine PMMM, as follows:

(1) OPM3 from PMI (Backlund et al. 2014; Jia et al. 2008);

(2) CMMI from SEI (Backlund et al. 2014; Jia et al. 2008);

(3) SPICE (Backlund et al. 2014; Sarshar et al. 1999);

(4) P2MM form OGC (Jia et al. 2008);

(5) PMM from PMSolutions (Jia et al. 2008);

(6) PM2 from Berkeley (Backlund et al. 2014);

(7) MMGP from Prado (Dragoni and Ghobril 2020; Neto et al. 2019; Santos et al. 2019);

(8) P3M3 (Backlund et al. 2014; Jia et al. 2008);

(9) PMM from Kerzner (Kwak et al. 2015);

From the analysis of those articles, it became clear that there is not a consensus about which MM should be used when assessing PMM in construction firms. Yet, MMGP Prado was the one that had only positive remarks. It was only verified by three articles (Dragoni and Ghobril 2020; Neto et al. 2019; Santos et al. 2019) and no comparison was made with any other model. At this stage, the authors reached the conclusion of Step 2 from Stage 2. Next, the aforementioned author's conclusions were analyzed and discussed.

\subsection{PMMM Applied in Construction Firms-Discussion on the Conclusions of the Articles}

Intending to identify the most suitable PMMM applied in the construction sector, the final step of Stage 2 was developed. Every author except Santos et al. (2019), Neto et al. (2019) and Dragoni and Ghobril (2020), concluded that the PMMM analyzed was not qualified to assess the project management capabilities of construction firms in a way capable of producing satisfactory results. Contingencies (Table 5) and potentiating factors (Table 6) are listed as follows: 
Table 5. Contingencies appointed by authors.

\begin{tabular}{llll}
\hline \multicolumn{1}{c}{ Contingency } & \multicolumn{1}{c}{ Observations } & Standard & Author \\
\hline & & PMM-PMS & \\
It was a question of organizational & OPM3 could not be directly applied & CMMI & Jia et al. (2008) \\
culture & because the organization had not & OPM3 & P2MM \\
& integrated OPM3 as a guide & P3M3 & \\
\hline
\end{tabular}

SPICE needed to be adapted in a way to become capable of responding

Inability to adapt according to organization structure and size

Lack of focus on a single PM methodology accordingly to the supply chain, and adapt its tools to each part of that chain according to its size, financial status and business model

The methodology should be a singular, cross-organizational, project management methodology

PM skills concentrated on a single manager rather than a project team
PM skills attained only by one resource

High degree of technical engineering skills among managers

Lack of evidence of PM practices
Managers provide no support in governance nor in organizational development because they devalue it

Inability to perform an assessment on PMMM when there are no PM practices whatsoever
SPICE Sarshar et al. (1999)

\begin{tabular}{cc} 
P3M3 (OGC) & \\
OPM3 & Backlund et al. (2014) \\
SPICE & \\
PM2 (Berkeley) & \\
P3M3 (OGC) & \\
OPM3 & Backlund et al. (2014) \\
SPICE & \\
PM2 (Berkeley) & \\
P3M3 (OGC) & \\
OPM3 & \\
SPICE & \\
PM2 (Berkeley) & \\
P3M3 (OGC) & \\
OPM3 & \\
SPICE & \\
PM2 (Berkeley) & \\
\hline
\end{tabular}

Table 6. Potentiating factors appointed by authors.

\begin{tabular}{llll}
\hline \multicolumn{1}{c}{ Potentiating Factors } & \multicolumn{1}{c}{ Observations } & Standard & Author \\
\hline Zero cost & $\begin{array}{l}\text { Free web-based app for model } \\
\text { implementation and analysis }\end{array}$ & MMGP Prado & Santos et al. (2019) \\
\hline Departmental/Corporate approach & $\begin{array}{l}\text { It can address only one department } \\
\text { across the whole organization or } \\
\text { address the organization as a whole }\end{array}$ & MMGP Prado & Santos et al. (2019) \\
\hline $\begin{array}{l}\text { Organizational context improvement } \\
\text { enabler }\end{array}$ & $\begin{array}{l}\text { It has a tool that enables effective } \\
\text { improvement in the organizational } \\
\text { context }\end{array}$ & MMGP Prado & Santos et al. (2019) \\
\hline $\begin{array}{l}\text { Promotes a project-based } \\
\text { organizational structure }\end{array}$ & $\begin{array}{l}\text { It has a tool that enhances project-based } \\
\text { organization structures }\end{array}$ & MMGP Prado & Santos et al. (2019) \\
\hline $\begin{array}{l}\text { Promotes the engagement of the } \\
\text { project team }\end{array}$ & $\begin{array}{l}\text { It has a tool that promotes effective } \\
\text { engagement by the project team }\end{array}$ & MMGP Prado & Santos et al. (2019) \\
\hline $\begin{array}{l}\text { Promotes the usage of information } \\
\text { systems }\end{array}$ & $\begin{array}{l}\text { It has a tool that promotes information } \\
\text { system usage }\end{array}$ & MMGP Prado & Santos et al. (2019) \\
\hline $\begin{array}{l}\text { Promotes the employment of PM } \\
\text { tools and techniques }\end{array}$ & $\begin{array}{l}\text { It has a tool that promotes the } \\
\text { employment of PM tools and } \\
\text { techniques }\end{array}$ & $\begin{array}{l}\text { It has a tool that promotes the ability to } \\
\text { strategically align project management }\end{array}$ & MMGP Prado \\
\hline $\begin{array}{l}\text { Promotes the ability to strategically } \\
\text { align project management }\end{array}$ & Santos et al. (2019) \\
\hline
\end{tabular}


In fact, the authors have presented numerous contingencies regarding the applicability of these PMMM, which will continue to be discussed. Through the analysis of Tables 2-4, it is clear that there are two MM that stand out from the others:

- OPM3, because it was the one that obtained more references in the course of the literature review (Berssaneti and Carvalho 2015; Kwak et al. 2015; Jia et al. 2008; Backlund et al. 2014; Pinto and Williams 2013; Khoshgoftar and Osman 2009). At the same time it was also the one that showed evidence on how it was developed, through a thorough and exhaustive Organizational Project Management Program developed over more than a decade under the umbrella of one of the major institutions regarding this domain the PMI (Cooke-Davies et al. 2001; Kwak et al. 2015);

- MMGP Prado, because it was the one that was able to produce satisfactory results, and no contingencies were mentioned for the application on construction companies whatsoever (Dragoni and Ghobril 2020; Neto et al. 2019; Santos et al. 2019).

Although the results of the previous analysis pointed out OPM3 and MMGP Prado as the most suitable candidates, it was important to obtain more feedback from the implementation of PMMM in construction environments. Even without using none of the aforementioned models, it was important to consider such conclusions/results. This fact becomes even more importance considering that the literature reviewed demonstrated a lack of evidence about the impact of the application of PMMM on the effectiveness of construction project management. Nevertheless, three papers were identified and analyzed and they mentioned contingency factors. One of them presented potentiating factors based on their findings.

In line with this, Stage 2 is considered concluded and the results show that there are two PMMM that fit better to assess project management capabilities in construction companies: OPM3 and MMGP Prado.

\section{Conclusions, Limitations and Future Research}

This research experienced some difficulties regarding finding a model within literature related to assessing project management maturity for construction firms, especially because there is a scarcity of information on this topic, as was mentioned previously. Except in the case of MMGP Prado, the authors found no other model that had been applied in a context of a construction project without having been subject to some sort of adjustments or without having experienced some conditioning factors.

This paper begins by presenting the state of art on the topic of PMMM. A description of the different aspects of the current PMMM were reviewed, combining knowledge from different domains. After this, the authors selected the ones that were applied in the construction sector. Based on the comparison analysis pursued, it was determined that MMGP Prado and the OPM3 models were considered the best models to assess PMM in construction organizations, taking into account that MMGP Prado was the only one applied within the construction sector that did not have any negative aspects considered. The OPM3 was chosen because it was the most cited PMMM across the literature reviewed and also because it showed evidence on how it was developed. This model has been exhaustively developed over more than a decade under the umbrella of one of the biggest institutions in regard to the domain of PM, the PMI.

Undoubtedly, this paper contributes in two ways. First it contributes to the knowledge base of PMMM. The literature review identified 39 PMMM, alongside the identification of the most suitable PMMM to be applied in a construction project, by the elements identified and adopted during this research, contributing to one of the biggest gaps in the literature on this matter.

The results of this research were possible on a basis of compromises in the comparability among PMMM. To determine what is important and what is not as important for each particular project/improvement case should always be one of the first pursued paths on any PMMM project. At the same time, one has to consider that each sector has its own particularities. Construction companies are undoubtedly in the project-oriented 
organization's territory and have their own particularities and attributes that must be taken into consideration for the sake of the adoption and implementation of PM methodologies and practices (not to mention the implementation of a PMMM). As an example, one can point out the number of stakeholders involved in these projects and their level of involvement or even know-how asymmetries that exist among contractors in the same project (in-plant resources, project dimension: physical-, financial-, or time-bound). Any of these variables can influence the choice of the most suitable PMMM to increase PM capabilities. Even historical issues play a significant role in these decisions. The degree of variability that exists in execution and project scope in certain types of projects can also significantly constrain the outputs of the project management. It is the authors view that for the sake of project efficiency gains, it is necessary to incorporate resource competency gains in-plant in order to make it possible for an organization to have a management team capable of making informed decisions, and to have the right tools and the proper resources to effectively assess and evaluate the project management capabilities. This way, the organization is capable of visualizing the different options available to effectively climb the ladder of the chosen PMMM.

It is expected that future research arising from this paper should focus on determining the best fit for assessing a specific segment of the construction sector. In line with this, it becomes necessary to determine what the characteristics of the organizations included the sector are, their attributes and competencies, as well as to comprehend their needs in terms of growth of maturity. After that, one should match those characteristics and attributes identified with possible contingencies and potentiating factors identified by this research in order to obtain a better understanding of the possible needs of an assessment project. Therefore, the authors consider it necessary to gather more information in order to select one of the PMMM identified in this paper as the best fit for assessing the project management capabilities of those particular construction firms. This should also make it easier to monitor the behavior throughout time, and to suggest adequate adjustments towards enhancing the projects' outputs and its future benefits.

Author Contributions: Conceptualization, F.M. and N.D.; Formal analysis, A.A. and T.B.; Investigation, F.M. and A.A.; Methodology, F.M. and T.B.; Supervision, N.D.; Visualization, A.A.; Writingoriginal draft, F.M.; Writing-review and editing, N.D. and T.B. All authors have read and agreed to the published version of the manuscript.

Funding: This research received no external funding.

Data Availability Statement: Not applicable.

Conflicts of Interest: The authors declare no conflict of interest.

\section{References}

Archibald, Russell D. 2013. A Global System for Categorizing Projects. IPMA Project Perspectives, 7. Available online: http:// russarchibald.com/GLOBAL\%20SYSTEM\%20FOR\%20CATEGORIZING\%20PROJECTS.pdf (accessed on 30 June 2021).

Backlund, Fredrick, Diana Chronéer, and Erik Sundqvist. 2014. Project Management Maturity Models-A Critical Review. ProcediaSocial and Behavioral Sciences 119: 837-46. [CrossRef]

Belt, Pekka, Annukka Oiva-Kess, Janne Harkonen, Matti Mottonen, and Pekka Kess. 2009. Organisational Maturity and Functional Performance. International Journal of Management and Enterprise Development 6: 147-64. [CrossRef]

Berssaneti, Fernando, and Marly Carvalho. 2015. Identification of Variables That Impact Project Success in Brazilian Companies. International Journal of Project Management 33: 638-49. [CrossRef]

Carcary, Marian. 2011. Design Science Research: The Case of the IT Capability Maturity Framework (IT CMF). Electronic Journal of Business Research Methods 9: 109-18.

Chen, Tao, Meiqing Fu, Rui Liu, Xuanhua Xu, Shenbei Zhou, and Bingsheng Liu. 2019. How Do Project Management Competencies Change within the Project Management Career Model in Large Chinese Construction Companies? International Journal of Project Management 37: 485-500. [CrossRef]

Christoph, Albrecht, and Spang Konrad. 2014. Project Complexity as an Influence Factor on the Balance of Costs and Benefits in Project Management Maturity Modeling. Procedia-Social and Behavioral Sciences 119: 162-71. [CrossRef]

Cook, Curtis R., and Marcello Visconti. 1998. Evolution of a Maturity Model—Critical Evaluation and Lessons Learned. Software Quality Journal 7: 223-37. 
Cooke-Davies, Terry, John Schlichter, and Christophe Bredillet. 2001. Beyond the PMBOK ${ }^{\circledR}$ Guide. Paper presented at Project Management Institute Annual Seminars \& Symposium, Nashville, TN, USA, November 1-10; Newtown Square: Project Management Institute. Available online: https://www.pmi.org/learning/library/organizational-model-maturity-body-knowledge-7822 (accessed on 22 July 2021).

Cruz, Carlos Oliveira, Patrícia Gaspar, and Jorge Brito. 2019. On the Concept of Sustainable Sustainability: An Application to the Portuguese Construction Sector. Journal of Building Engineering 25: 100836. [CrossRef]

Dragoni, Helio, Jr., and Alexandre Nabil Ghobril. 2020. Proposta de Melhoria Do Desempenho Por Meio Da Maturidade Em Gerenciamento de Projetos. Revista Inovação Projetos e Tecnologias 8: 71-82. [CrossRef]

Gardiner, Tony, Charles Weber, and Bill Curtis. 2008. Business Process Maturity Model (BPMM) Version 1.0. Needham: Open Management Group. Available online: https:/ /www.omg.org/spec/BPMM/1.0/PDF (accessed on 30 June 2021).

Hamel, Florian, Thomas Ph. Herz, Falk Uebernickel, and Walter Brenner. 2013. IT Evaluation in Business Groups: A Maturity Model. In Proceedings of the ACM Symposium on Applied Computing. New York: Association for Computing Machinery, pp. 1410-17. [CrossRef]

Hillson, David. 2003. Assessing Organisational Project Management Capability. Journal of Facilities Management 2: 298-311. [CrossRef]

Ibbs, C. William, Justin M. Reginato, and Young Hoon Kwak. 2007. Developing Project Management Capability: Benchmarking, Maturity, Modeling, Gap Analyses, and ROI Studies. In The Wiley Guide to Project Organization E Project Management Competencies. Hoboken: Wiley.

ISO/IEC. 2020. ISO/IEC TS 33060:2020 (EN), 1st ed. Geneva: ISO.

Jia, Guangshe, Li Cao, Jianguo Chen, Shuisen Zhou, and Jin Wang. 2008. Application of Organizational Project Management Maturity Model (OPM3) to Construction in China: An Empirical Study. Paper presented at the International Conference on Information Management, Innovation Management and Industrial Engineering, ICIII 2008, Taipei, Taiwan, December 19-21.

Kerzner, Harold. 2016. Gestão de Projetos: As Melhores Práticas, 3rd ed. Taipei: Bookman.

Khoshgoftar, Mohammad, and Omar Osman. 2009. Comparison of Maturity Models. Paper presented at 2009 2nd IEEE International Conference on Computer Science and Information Technology, ICCSIT 2009, Beijing, China, August 8-11.

Kwak, Young Hoon, Hessam Sadatsafavi, John Walewski, and Nigel L. Williams. 2015. Evolution of Project Based Organization: A Case Study. International Journal of Project Management 33: 1652-64. [CrossRef]

Luftman, Jerry N. 2011. Assessing Business-IT Alignment Maturity. Strategic Information Technology. Hershey: IGI Global. [CrossRef]

Melenovsky, Michael James, and Jim Sinur. 2006. BPM Maturity Model Identifies Six Phases for Successful BPM Adoption. Stamford: Gartner, pp. 1-14.

Monteiro de Carvalho, Marly, Roque Rabechini Jr., Marcelo Schneck de Paula Pessôa, and Fernando Barbin Laurindo. 2005. Equivalência e Completeza: Análise de Dois Modelos de Maturidade Em Gestão de Projetos. Revista de Administração—RAUSP 40: 289-300.

Nascio. 2009. Data Governance Part II : Maturity Models—A Path to Progress. NASCIO Governance Series; Lexington: Nascio. Available online: https:/ / www.nascio.org/wp-content/uploads/2019/11/NASCIO-DataGovernancePTII.pdf?_cf_chl_managed_tk_ _=13d6db34ac6c7de92ae167945a33c411c85e79a4-1624389820-0-AQzA9QEBIb_3aenaC2KcMZHxY_5OGG3Q9UBoxUa6Lh0s3 _FAt0lBks5M2-1qlCSLopTIWuZzLF4gN77wM0FeW7zXXdJih1rWl_0 (accessed on 22 July 2021).

Neto, Antonio, Bento Santos Jr., Alcides Araújo Filho, Adriele Souza, and Fabiane Serpa. 2019. Avaliação Do Grau De Maturidade Em Gerenciamento De Projetos No Setor De Planejamento Da Empresa Mf Tecnologia Predial. In Engenharia de Produção: Vetor de Transformação Do Brasil. Ponta Grossa: Atena Editora, pp. 119-32. [CrossRef]

Niessink, Frank, Viktor Clerc, Ton Tijdink, and Hans Van Vliet. 2005. The IT Service Capability Maturity Model. Management. Vol. 2007. Available online: http:/ / www.itservicecmm.org/doc/itscmm-1.0rc1.pdf (accessed on 22 July 2021).

Nikjow, Mohammad Ajmal, Li Liang, Xijing Qi, and Samad Sepasgozar. 2021. Engineering Procurement Construction in the Context of Belt and Road Infrastructure Projects in West Asia: A SWOT Analysis. Journal of Risk and Financial Management 14: 92. [CrossRef]

OPM. 2013. OPM $3^{\circledR}$. Organizational Project Management Maturity Model, 3rd ed. Newtown Square: Project Management Institute.

OPM. 2018. OPM (Organizational Project Management) The Standard for Organizational Project Management, 1st ed. Newtown Square: Project Management Institute.

Packendorff, Johann, and Monica Lindgren. 2014. Projectification and Its Consequences: Narrow and Broad Conceptualisations. South African Journal of Economic and Management Sciences 17: 7-21. [CrossRef]

Parviainen, Päivi, Juha Takalo, Susanna Teppola, and Maarit Tihinen. 2009. Model-Driven Development Processes and Practices. VTT Working Papers. Espoo: VTT Technical Research Centre of Finland Ltd.

Pinto, J. 2013. 100 Organizational Improvements Using OPM3®. Paper presented at PMI®Global Congress 2013-North America, New Orleans, LA, USA, October 29; Newtown Square: Project Management Institute.

Pinto, José, and Nigel Williams. 2013. Country Project Management Maturity Capability. Paper Presented at PMI®Global Congress 2013-EMEA, Istanbul, Turkey, April 22-24.

Prado, Darci. 2015. Maturidade Em Gerenciamento De Projetos, 3rd ed. Nova Lima: Falconi Editora, Available online: https://www. falconi.com/wp-content/uploads/2013/05/Sumario_Maturidade_GP1.pdf (accessed on 1 July 2021).

Prado, Darci. 2016. A Importância Da Evolução Da Maturidade Em Gerenciamento de Projetos. Available online: https:// maturityresearch.com/modelo-prado-mmgp/ (accessed on 19 July 2020).

Pretorius, S., H. Steyn, and J. C. Jordaan. 2012. Project Management Maturity and Project Management Success in the Engineering and Construction Industries in Southern Africa. South African Journal of Industrial Engineering 23: 1-12. [CrossRef] 
Proença, Diogo, and José Borbinha. 2016. Maturity Models for Information Systems-A State of the Art. Procedia Computer Science 100: 1042-49. [CrossRef]

Proença, Diogo, Ricardo Vieira, and José Borbinha. 2016. A Maturity Model for Information Governance. In Research and Advanced Technology for Digital Libraries. Lecture Notes in Computer Science (Including Subseries Lecture Notes in Artificial Intelligence and Lecture Notes in Bioinformatics). Cham: Springer, vol. 9819, pp. 15-26. [CrossRef]

Santos, Danielle Freitas, Fernando Schramm, and Vanessa B. Schramm. 2019. Análise Da Maturidade Em Gestão de Projetos de Uma Empresa Da Construção Civil Utilizando a Metodologia MMGP. Interfaces Científicas 3: 49-64. [CrossRef]

Sarshar, Marjan, Matthew Finnemore, Richard Haigh, and Jack Goulding. 1999. SPICE: Is a Capability Maturity Model Applicable in the Construction Industry? Paper presented at 8th International Conference on Durability of Building Materials and Components, Vancouver, BC, Canada, May 30-June 3; Ottawa: National Research Council Canada.

Silva, Cláudia, Pedro Ribeiro, Eduardo B. Pinto, and Paula Monteiro. 2021. Maturity Model for Collaborative R\&D University-Industry Sustainable Partnerships. Procedia Computer Science 181: 811-17. [CrossRef]

Söderlund, Jonas. 2014. Project-Based Organizations: What Are They? In The Psychology and Management of Project Teams. Stroud: Newgen, pp. 74-100.

Yazici, Hulya Julie. 2010. Role of Project Maturity and Organizational Culture on Project Success. Paper presented at PMI®Research Conference: Defining the Future of Project Management, Washington, DC, USA, July 11-14; 2010 PMI Research \& Education Conference, no. September 2009: 1-14. Available online: ftp://ftp.ags.com/downloads/PMIC/pdfs/PPS03.pdf (accessed on 22 July 2021). 